\title{
Urgences
}

\section{Dormir dans un wagon rose avec Rimbaud (extraits)}

\section{Line Arsenault}

Numéro 9, 1er trimestre 1984

URI : https://id.erudit.org/iderudit/025135ar

DOI : https://doi.org/10.7202/025135ar

Aller au sommaire du numéro

Éditeur(s)

Urgences

ISSN

0226-9554 (imprimé)

1927-3924 (numérique)

Découvrir la revue

Citer ce document

Arsenault, L. (1984). Dormir dans un wagon rose avec Rimbaud (extraits).

Urgences, (9), 43-47. https://doi.org/10.7202/025135ar d'utilisation que vous pouvez consulter en ligne.

https://apropos.erudit.org/fr/usagers/politique-dutilisation/ 


\title{
LINE ARSENAULT
}

\section{DORMIR DANS UN WAGON ROSE AVEC RIMBAUD}

\author{
(extraits)
}


Et quand l'été était. Un arrivage flou tamisé de soleil. Quelques couleurs muries par la douceur du temps. Quelques amours adoucies par la chaleur des vents.

Quand l'été. Jeux d'enfants. Châteaux de sable. Plage blanche brûlante. Herbages salés en dentelles d'écume.

$\mathrm{J}$ 'ai fait la cour à tous les princes de saison. Quand les forêts sombres, les clairières, les champs de blés longs, les berges nous avaient vus passer. Mon maillot couleur chair que la mer avait rendu transparent. Mes bijoux brillants. Mes couleurs dépassées. Le coucher du jour. Silences.

J'ai fait le tour des îles blondes ou le soleil collait les hommes à la terre. J'ai fait le tour des hommes blonds.

Mais je n'ai pas entendu tourner les manèges ni courir les chevaux de bois. Ni pleurer les enfants sages qui voyaient s'envoler leur ballon.

Je n'ai pas pris part à la fête. Je n'ai pas répondu à l'invitation. Je suis partie en voyage dans un pays tres beau. Et je n'ai pas vu pleurer les enfants qui voyaient s'envoler leur ballon. Et je n'ai pas entendu courir en rond les chevaux de bois. L'été. 


\section{II}

Cela commence comme un vrai commencement. Le soleil est chaud encore sur ma peau de septembre. Et j'avance. Ce temps est bon comme un été qui n'en finirait plus. Je t'ai rêvé. Nous avons passé la nuit ensemble.

Cela commence tel un véritable été. La neige fondue. Le printemps exilé. Quelques feuilles mortes roulant au bord du chemin gris. Sans vent. Le soleil. Qu'aurais-tu fait à sa place? Tu aurais touché mon visage, tu serais entré dans mes yeux. Tu m'aurais donné toute la dernière chaleur de la saison.

J'avance. Je voudrais marcher ainsi toute la vie. Je pourrais encore. Allant droit vers ce soleil de septembre à cinq heures. Lumière et douceur. Qu'aurais-tu fait à ma place? Ah, que le temps ne s'est-il pas arrêté là? Pendant que cette saison durait. Un jour ou deux.

Cela commence comme un vrai commencement. Le lendemain le jour se lève. Doux. Et, tremblants encore dans une rêverie légère, nous nous enchevêtrons. Parfaitement! 
III

Cela se termine comme un coucher de lune. Dans le ciel du soir. Sans bruits. Indiscrètement. En silence. Sans que personne ne sache. Les émois. Les attentes. Le désir qui passe à travers la nuit.

Je l'entend passer quand je ne dors pas. Je l'entend dormir quand je passe.

Tout se termine. Telle une saison qui se retire derrière le rideau. L'autre éparpille quelques feuilles déchirées d'un livre de bois vert. Déracine quelques couleurs dans l'espace. Déménage quelques valises refroidies. La saison part en voyage. Revient au printemps et défait ses bagages.

Tout se termine un peu. Comme un conte. Une histoire que les enfants pourraient regarder un jour de pluie. De belles images. Un grand livre qui tient sur les genoux. Tout seul.

C'est tout. On ne sait pas trop bien la fin de I'histoire. Mais tout se termine. Et on s'endort sur les dernières pages d'un livre grand ouvert sur les genoux. C'est comme ça. 


\section{IV}

II est un peu tard. Pour une invitation. II est minuit passé. Je ne bouge plus. J'invente ma dernière nuit dans une mémoire mal éclairée. II y a longtemps que je n'ai pas pleuré je pense. Pourquoi?

II est un peu tard mais il m'arrive de rester éveillée. Longtemps jusque dans le grand silence. Longtemps et de m'éveiller entre des rêves flous et violents. Et ce soir je voudrais faire l'amour dans le grand espace. Sous les grands projecteurs de la rue en janvier, mais pas dans la froide neige. Sur le grand quai glacé mais avec quelques draps dessus. Et j'irais sur tes reins, vaillamment et tu prendrais mon ombre dans tes mains. Ma tête un peu penchée en arrière.

II est un peu tard pour s'endormir maintenant. Et j'ai toujours dans ma tête des musiques de barbarie. Comme le début d'un cirque. Ou de quelque chose qui m'aurait toujours facinée.

Je ne sais pas quelle heure il peut être. Tout est comme I'hiver. La saison d'avant je n'étais pas ici. Je ne sais pas quelle heure il est avant d'aller dormir. J'invente un pays de sable. Je m'étire jusqu'à la falaise et je m'envole. C'est toujours comme ça.

Maintenant je sais que le cirque ne viendra pas cette nuit. Parce qu'il est trop tard pour le dernier spectacle. L'homme du guichet, lui, dort depuis longtemps.

J'aurais crû qu'on puisse voir. Une présentation particulière. Nous seuls avec les funambules et les clowns que je n'aime pas. Nous et les cris de joie. Dans les grands yeux des enfants qui croient que le temps s'est arrêté.

J'étais toute prête à sortir. J'avais mis mes gants de broderie. Mes perles rares, le renard que ma mère m'aurait prêté. Et un parfum extrait du tour du monde. En cologne.

Et ouvert toute grande la porte. Baignée dans la lumière écrue du porche. J'attendais qu'enfin quelqu'un passe...

- Vous allez loin?

Même!... Je pensais qu'il y avait pleine lune.

Tout quoi! 